\title{
Awareness and Practice of Junk Foods among Adolescents in Secondary Level Students
}

\author{
Radha Paudel and Sarita Shrestha
}

College of Nursing, Nepalese Army Institute of Health Sciences, Sanobharyang, Kathmandu, Nepal

\begin{abstract}
Introduction: Junk food consumption among adolescents has become a serious issue that may lead to harmful effects on health. Dietary patterns of people are shifting from homemade foods to junk foods. Therefore, this study was undertaken to assess the awareness and practice of junk foods among adolescents.

Methods: A descriptive cross-sectional study was conducted among adolescents of secondary level students. A simple random sampling technique was used to select the sample and the sample size was 237. Data collection was done from April 15, 2019 to May 14, 2019. A set of semi-structured selfadministered questionnaire was used for data collection. Descriptive and inferential statistics were used to analyse and interpret the findings.

Results: The findings showed that more than three-fifth $(67.9 \%)$ of adolescents had a moderate level of awareness about junk foods. Half (49.4\%) of them consumed junk foods highly. All (100\%) adolescents have consumed junk foods regularly whereas two-fifth (42.2\%) replaced meals once a week with junk foods. Four-fifth $(82.3 \%)$ of adolescents did not bring tiffin from home. There was no significant association between the awareness and practice of junk foods $(\mathrm{p}<0.05)$.

Conclusions: This study concludes that most of the adolescents possessed a moderate level of awareness of junk foods. Majority of them did not bring tiffin from their home. Around half of them consumed junk foods in their daily life. Majority of them were aware of junk foods, although they still consumed junk foods.
\end{abstract}

Key words: adolescents; awareness; health effects; junk foods; practice; secondary school

Correspondence: Radha Paudel, College of Nursing, Nepalese Army Institute of Health Sciences, Sanobharyang, Kathmandu, Nepal, Email: radha2739@gmail.com

DOI: $10.3126 / \mathrm{mjsbh} . v 20 \mathrm{i} 2.30309$

Submitted on: $2020-07-26$

Accepted on: 2021-05-31

This work is licensed under creative common license:

http://creativecommons.org/licenses/by-nc-nd/4.0/ C MJSBH 2020 


\section{INTRODUCTION}

Junk foods contain a lot of unhealthy ingredients which are unsafe not just for children, but for people of all ages. The transition in lifestyle and dietary habits may be responsible for this trend and it is directly or indirectly leading to rise of many non-communicable diseases. ${ }^{1}$ Most parents are hardly aware of the fact that local foods produced by them are far cheaper and more nutritious. ${ }^{2}$ Despite this fact, consumption trend of junk foods is increasing all over the world.

Junk food consumption and obesity in childhood are emerging as a global epidemic. Various television and other commercials have such an impact on schoolchildren that they consider eating fatty foods as a fashion. ${ }^{3}$ This impacts on psychological, physical, and economic conditions of adolescents, and also leads to various non communicable diseases like type 2 diabetes mellitus, hypertension, hypercholesterolemia etc. ${ }^{4}$ Reduction of consumption of junk foods and regular intake of nutritious and healthy food can have long term impact on the children's present and future. ${ }^{5}$

The present study thus was conceptualised among adolescents to assess their existing awareness and practice of junk foods among adolescents. This study can be beneficial in improving the health and wellbeing of adolescents. So it may be useful to prepare a nutritional policy to improve the nutritional status of adolescents in schools.

\section{METHODS}

A descriptive cross-sectional study was conducted to assess the existing awareness and practice of adolescents regarding junk foods. Tilingatar higher secondary school, Dhapasi secondary school, and Bansbari secondary school of Kathmandu were selected randomly from a total of 600 Government high schools. The students studying in grades eight, nine and ten were taken as study population. The class sections were selected by a simple random technique. Data was collected in the classroom setting from April 15, 2019 to May 14, 2019. The total sample calculated was 237 by using the given formula at $95 \%$ confidence level and with $5 \%$ of marginal error assuming; $\mathrm{P}=0.5 \%$. A semistructured tool was developed from reviewing different literature by researchers. Selfadministered semi-structured questionnaire was used for data collection.

The data were entered and then analysed in SPSS. The frequencies, percentage, mean, and standard deviation were used as a part of descriptive statistics; the chi-square test was used to establish the association between awareness and practice of junk foods. A p-value of less than 0.05 was used for statistical significance. The level of awareness was measured by calculating the percentages of the correct answers and classified into three categories as an inadequate level of awareness was considered as below $50 \%$, a moderate level was $50-75 \%$ and above $75 \%$ was considered as a high level of awareness. ${ }^{6}$ The level of practice above mean was considered as the high practice, and below mean was considered as the low practice.

The ethical approval was taken from the Institutional Review Committee of the Nepalese Army Institute of Health Sciences (NAIHS) and permission was obtained from the schools. Verbal consent was taken from each student and the assent was obtained for below 16 years. The purpose and objectives of the study were explained to the students. The respondents were informed about their right to refuse or to withdraw at any time during the study.

\section{RESULTS}

The mean age of the respondents was $15.12 \pm 1.33$ years. More than half $(58.6 \%)$ were females and nearly three fifth $(72.2 \%)$ of them were Hindus. Three fourth $(74.3 \%)$ was from the nuclear family. Three fourth $(75.1 \%)$ respondents stayed with their parents and the majority (70\%) of them had sufficient income for day-to-day expenditure for one year.

Nearly three fourth $(72.6 \%)$ of the respondents understood the correct meaning of junk foods. All $(100 \%)$ of them were familiar with added chemicals and additives in junk foods but only $43.5 \%$ of the respondents knew that Monosodium Glutamate (MSG) (Azinamotto) was a commonly used flavour enhancer in junk foods. Thirty eight percent of respondents were familiar that junk foods had flavour enhancers added to them which helped in satisfying cravings. A vast majority 
Table 1. Respondents' Awareness of Junk Foods $(\mathrm{n}=237)$

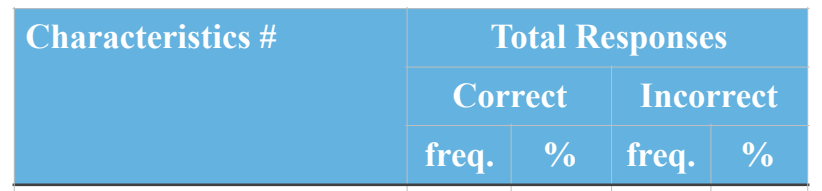

Meaning of junk foods

Those commercial foods with little nutritive value

Composition of Junk foods

High sodium, fatty acid, sugar, foods addictive

Added chemicals and additives in junk food

Yes \#

Commonly used flavor enhancer

Monosodium Gultamate (MSG)

/ (Azinamotto)

Contain of junk foods

High calorie

Contents rich in junk foods

Calories, salt and fat

Food manufactures use to make junk foods

More additive

Junk foods increases

Salivation

Food that increases risk of diabetes

Potato chip

Reason for appealing many people

It is full of flavor and satisfies cravings

Clue to decrease consumption of junk foods habit

Avoid buying processed and packaged foods

Aware the health effects of junk foods

\begin{tabular}{|l|l|l|l|}
\hline 48 & 20.3 & 189 & 79.7
\end{tabular}
Table 2. Respondents' Practice of Junk Foods $(\mathrm{n}=237)$

\begin{tabular}{|l|l|l}
\hline Characteristics & \multicolumn{2}{|c|}{ Total Responses } \\
& Frequency & $\%$ \\
\hline
\end{tabular}

Frequency of meals replace by junk foods per week

One $\quad 100 \quad 42.2$

Sometimes $\quad 47 \quad 19.8$

Never

$\begin{array}{lll}\text { Not at all } & 47 & 19.8\end{array}$

Common place to consume junk foods

Home

$57 \quad 24.1$

School

33.3

On the way

Restaurants

Other places

Types of junk foods consume*

Chocolates

Panipuri

$172 \quad 72.6$

Noodles

$164 \quad 69.2$

Potato chips

$149 \quad 62.9$

Cold drinks

123

51.9

Person provide money for junk foods

$\begin{array}{lrr}\text { Mother } & 150 & 63.3 \\ \text { Father } & 45 & 18.9 \\ \text { Grand parents } & 20 & 8.5 \\ \text { Sisters/brothers } & 15 & 6.4 \\ \text { Others } & 7 & 2.9\end{array}$

Money spent for junk foods daily (Nepalese Rupees)

Below Rs. $20 \quad 91 \quad 38.4$

Rs. $21-40 \quad 74 \quad 31.2$

Rs. $41-60 \quad 29 \quad 12.2$

Above Rs. $60 \quad 43 \quad 18.2$

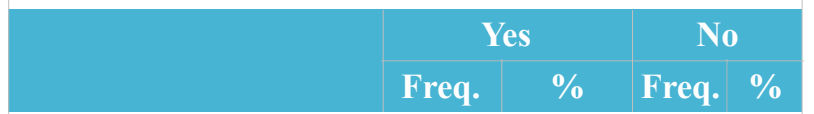

Consumption of junk $\quad 237 \quad 100.0 \quad-\quad$ foods regularly

$\begin{array}{lllll}\text { Check nutrient value } & 113 & 47.6 & 124 & 52.4\end{array}$

$\begin{array}{lllll}\text { Increasing of habit to } & 169 & 71.3 & 68 & 28.7\end{array}$ use junk foods

$\begin{array}{lllll}\text { Bring tiffin box from } & 42 & 17.7 & 195 & 82.3\end{array}$ home

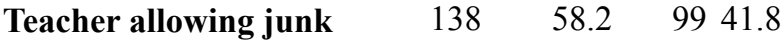
foods in school

$\begin{array}{lllll}\text { Parents' approval for } & 230 & 97.0 & 3 & 3.0\end{array}$ junk foods

$\begin{array}{lllll}\text { Satisfaction after eating } & 237 & 100.0 & -\end{array}$ junk foods

$\begin{array}{lllll}\text { Like taste of junk foods } & 217 & 91.5 & 20 & 8.5\end{array}$

$\begin{array}{llllll}\text { Easy accessibility of } & 237 & 100.0 & -\end{array}$

junk food in school

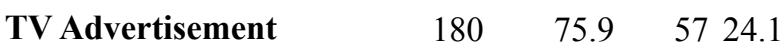

influences to eat junk

foods

$\begin{array}{lllll}\text { Price influences to eat } & 165 & 69.6 & 72 & 30.4\end{array}$ junk foods

\section{.} 8.9 4

9


Table 3. Respondent's Level of Awareness and Practice of Junk Foods

\begin{tabular}{|c|c|c|}
\hline Level of Awareness & Freq. & $\%$ \\
\hline Inadequate Level $(<50 \%)$ & 57 & 24.1 \\
\hline Moderate Level (50 - 75\%) & 161 & 67.9 \\
\hline High Level (> 75\%) & 19 & 8.0 \\
\hline Total & 237 & 100.0 \\
\hline Level of Practice & Freq & $\%$ \\
\hline High practice & 117 & 49.4 \\
\hline Low practice & 120 & 50.6 \\
\hline Total & 237 & 100 \\
\hline
\end{tabular}

(92.8\%) of the respondents were aware of the harmful effects of junk foods (Table 1).

Our study showed that $42.2 \%$ of them replaced meals once a week with junk foods. Likewise, $33.3 \%$ had consumed junk foods at school. Nearly three fourth $(72.6 \%)$ of the respondents ate chocolates followed by paanipuri which was $70 \%$. More than three fifth $(63.3 \%)$ were taking money from their mother to purchase junk foods and they spent below 20 Rs on junk foods daily. All (100\%) consumed junk foods regularly. Almost half $(47.6 \%)$ of them checked nutrients values. Similarly, less than three fourth $(71.3 \%)$ increased the habit of using junk foods. Very few (17.7\%) bought their own tiffin from home. More than half $(58.2 \%)$ of the teachers allowed junk foods in school and a vast majority (97.0\%) of parents gave permission to eat junk foods. A vast majority (91.5\%) of them answered that the taste was the prime cause that motivated them to consume junk foods followed by television advertisements (75.9\%) (Table 2).

More than three fifth (67.9\%) of the respondents had a moderate level of awareness, one fourth $(24.1 \%)$ had an inadequate level of awareness and few $(8.0 \%)$ had a high level of awareness. More than half (50.6\%) of respondents had a low practice of consuming junk foods whereas, nearly half (49.4\%) had a high practice of consuming junk foods (Table 3).

There was no significant association between the level of awareness and practice of junk foods $(\mathrm{P}<$ 0.05) (Table 4).
Table 4. Association between Respondents' Level of Awareness and Practice of Junk Foods

\begin{tabular}{|c|c|c|c|c|c|c|}
\hline \multirow{3}{*}{$\begin{array}{l}\text { Level of } \\
\text { Awareness }\end{array}$} & \multicolumn{4}{|c|}{ Level of Practice } & \multirow{3}{*}{$\begin{array}{c}\text { Chi } \\
\text { square } \\
\text { value }\end{array}$} & \multirow{3}{*}{$\begin{array}{c}\text { P- } \\
\text { value }\end{array}$} \\
\hline & \multicolumn{2}{|c|}{$\begin{array}{l}\text { High } \\
\text { Practice }\end{array}$} & \multicolumn{2}{|c|}{$\begin{array}{c}\text { Low } \\
\text { Practice }\end{array}$} & & \\
\hline & $\mathbf{f}$ & $\%$ & f & $\%$ & & \\
\hline $\begin{array}{l}\text { High and } \\
\text { moderate } \\
\text { level }\end{array}$ & 90 & 50 & 90 & 50 & 0.120 & 0.729 \\
\hline $\begin{array}{l}\text { Inadequate } \\
\text { level }\end{array}$ & 27 & 47.36 & 30 & 52.64 & & \\
\hline
\end{tabular}

\section{DISCUSSION}

The current study showed that nearly three fourth $(72.6 \%)$ of the adolescent students knew the correct meaning of junk foods. A vast majority (91\%) of them consumed junk foods because of the taste. A similar study conducted in Nepal reported that $79.6 \%$ of the respondents were aware of the meaning of junk foods and $91 \%$ of them consumed junk foods for taste. ${ }^{7}$ A study conducted in India revealed a similar finding to the present study that $100 \%$ of the students were consuming junk foods. However, the frequency and quantity varied. ${ }^{7}$ The present study indicated that all the students (100\%) consumed junk foods regularly. This study revealed that $75.9 \%$ of the students were motivated for the consumption of junk foods due to $\mathrm{TV}$ advertisements; however, a study conducted in India as well as in Iran was inconsistent with our study. Both studies reported $54 \%$ and $51.9 \%$ of the respondents were highly motivated for junk foods due to TV advertisements. 5,9 This might be the effect of the ban of television advertisement in those countries.

In our study, most $(91.5 \%)$ of the students were motivated to consume junk foods due to taste as well as easy accessibility (100.0\%). This finding is consistent with another study conducted in Nepal which stated that the reasons for consumption of junk foods were due to better taste $(82.9 \%)$, and easy availability $(38.1 \%) .{ }^{10}$

The present study illustrated that $33.3 \%$ of the students had consumed junk foods at school, $30.8 \%$ had consumed on their way to home and $24.1 \%$ at 
home. This is in contrast to another study conducted in Nepal which showed that $91.5 \%$ consumed junk food in school and $8.5 \%$ consumed it at home. Another similar study reported that $100 \%$ consumed junk food in their school as it was allowed. ${ }^{8}$ This study also showed that $58.2 \%$ of teachers allowed to consume junk foods at school. Similarly, the current study depicted that $38.4 \%$ of the respondents had spent less than 20 Nepalese Rupees for purchasing junk foods daily. This finding is inconsistent with another study conducted in Nepal that showed the average money spent on junk food was 31 Nepalese Rupees per day. ${ }^{10}$

This study revealed that almost all $(92.8 \%)$ of the adolescents were aware of the harmful effects of junk foods on health. Our finding is in corroboration with a research conducted in India which reported $87 \%$ of the respondents were well aware of the side effects of these fast/junk foods. ${ }^{8}$ We found that $8.0 \%$ of respondents had a high level of awareness, $67.9 \%$ of the respondents had a moderate level of awareness and $24.1 \%$ had an inadequate level of awareness. However, our finding is inconsistent with another study conducted in India which revealed that $43.7 \%$ of the teenagers had adequate knowledge, $13.3 \%$ had moderate and $0.4 \%$ had poor knowledge. ${ }^{11}$ This variation could be resulted due to the different socioeconomic and geographical scenario between the two study places. The current study illustrated that nearly half $(49.4 \%)$ of the students had a poor practice of junk foods. It means that the adolescents consumed junk food highly. This finding was different from another study that showed a higher proportion of junk food consumption among adolescents (93\%). ${ }^{12}$ Similarly, another study reported that junk food eating habits of school children in Delhi was found among $60-70 \%$ of children. ${ }^{10}$ The difference in the consumption of junk foods is determined by the taste, availability, affordability, and by home and school environmental factors. Hence, the teacher's and parent's role is important to control consumption of junk foods.

The study revealed that $92.8 \%$ of the respondents were aware of the harmful effects of junk foods. This finding was not supported by the study conducted in India which showed that only $70 \%$ of students were aware of the harmful effects and its impact on human health. Similarly, this study illustrated that $47.6 \%$ of the respondents checked the quality of nutrients on junk food packages but another study conducted in India did not supported this finding and reported that only $18 \%$ of the respondents checked the quality at all. ${ }^{13}$ This shows the variation among the two study population, perhaps due to different geographic, socioeconomic and cultural differences.

The present study depicted that there is no significant association between the level of awareness and practice of junk foods $(\mathrm{P}<0.05)$. Taste, convenience and affordability were the foremost preference criteria for high consumption of junk foods among adolescents. Most of the students had a moderate awareness about junk foods and most had formed the habit of using junk foods in their daily life. On the other hand, parents also encouraged the use of junk foods because of their busy schedule and school also encouraged them to eat junk foods on school premises. They brought junk foods in the classroom without any restriction from teachers and have eaten at the tiffin-time in the group.

\section{CONCLUSIONS}

Most of the adolescents possessed a moderate level of awareness about junk foods and nearly half of them had a high consumption of junk foods in their practice. The main motivating factors for the consumption of junk foods were satisfaction, taste and accessibility. They were well aware about the health effects of junk foods but they prefer to eat junk foods daily instead of homemade foods. Therefore, the main role of parents and teachers is to discourage the use of junk foods and encourage them to use more effective, safe and healthy balanced diet.

\section{ACKNOWLEDGMENTS}

The authors would like to express gratitude to the NAIHS for providing grants in this research. Also thanking the principal and student of three selected schools of Kathmandu for granting the permission to conduct this study. 
To cite this article: Paudel R, Shrestha S. Awareness and Practice of Junk Foods among Adolescents in Secondary Level Students. MJSBH. 2021;20(2):104-9.

Conflict of Interest: None declared

\section{REFERENCES}

1. Mandoura N, Al-Raddadi R, Abdulrashid O, Shah HB, Kassar SM, Hawari AR, et al. Factors associated with consuming junk food among Saudi adults in Jeddah city. Cureus. 2017;9(12):1-5. DOI: https://doi.org/10.7759/ cureus. 2008

2. Ashakiran S, Deepthi R. Fast Foods and their impact on health. JKIMSU. 2012;1(2):22-8. Available from: https:// www.researchgate.net/publication/285169531

3. Sakthipriya E, Ramesh L. Influence of Television Advertisement on Unhealthy Food Preferences among Children. IJSR. 2016;5(9):1098-102. Available from: https://www.ijsr.net/search_index_results_paperid.php? $\mathrm{id}=$ ART20161741

4. Antony M, Bhatti RK. Junk food consumption and knowledge about its ill effects among teenagers: a descriptive study. IJSR. 2015;4(6):1133-6. https://www.ijsr.net/archive/v4i6/SUB155404.pdf

5. Joshi HA, Jethva VJ, Patel N. Changing food pattern in adolescents and impact on health. IJMSPH. 2014;3(12): 1442-5. DOI: https://doi.org/10.5455/ijmsph.2014.030920141

6. Khongrangjem T, Dsouza SM, Prabhu P, Dhange VB, Pari V, Ahirwar SK, et al. A study to assess the knowledge and practice of fast food consumption among Pre-University students in Udupi Taluk, Karnataka, India. CEGH. 2018; 6(4):172-5. DOI: https://doi.org/10.1016/j.cegh.2017.11.003

7. Sapkota SD, Neupane S. Childhood Poisoning, Junk Food Consumption among Secondary Level Students, Chitwan. J Nepal Paediatr Soc. 2017;37(2):147-52. DOI: https://doi.org/10.3126/jnps.v37i2.17081

8. Nayak RK. Pattern of fast or junk food consumption among medical students of north Karnataka- a cross sectional study. Int J Community Med Public Health 2020;7:1839-42. DOI: https://doi.org/ 10.18203/2394-6040.ijcmph20201991

9. MoradiLatreyi S, Mirhadyan L, Pasha A, KazemnezhadLeili E. Junk Food Consumption Among High School Students in Iran: The Role of Food Advertising. J Holist Nurses Midwifery. 2020;30(2):70-7. DOI: https://doi.org/ 10.32598/jhnm.30.2.70

10. Chalise B. Junk food prevention education package intervention and its effect on behavioural intention among students of kagesworimanohara municipality, Kathmandu district, Nepal. MOJ Public Health. 2018;7(3):123-7. DOI: https://doi.org/10.15406/mojph.2018.07.00217

11. Akila A. Knowledge of teenagers on fast food consumption in weight gain. IJPBS. 2016:6(1):71-6. DOI: https:// www.ijpbs.com/ijpbsadmin/upload/ijpbs_572a405a9a9fb.pdf

12. Vinay Gopal J, Sriram S, Kannabiran K, Seenivasan R. Student's perspective on junk foods: Survey. SJPH. 2012; 7(1):21-5. DOI: https://www.academia.edu/14789391/Students_perspective_on_junk_foods_Survey

13. Singh UK, Gautam N, Bhandari TR, Sapkota N. Educational Intervention of Intention Change for Consumption of Junk Food among School Adolescents in Birgunj Metropolitan City, Nepal, Based on Theory of Planned Behaviours. JNM. 2020;2020. DOI: https://doi.org/10.1155/2020/7932324 